\title{
ECOLOGICAL ASSESSMENT OF EPIDEMOLOGICAL CONDITIONS IN THE FOREST ECOTONE OF CROSS RIVER STATE
}

\author{
Being a Research Project Undertaking for Tertiary Education Trust \\ Fund(TETFUND Abuja Nigeira) \\ Otibu Godwin(Ph.D $)^{\mathrm{a}}$ Eju Patrick Ekuri ${ }^{\mathrm{b}}$ Ukpata, Mathias Oko ${ }^{\mathrm{c} *}$ \\ a okwilliams55@gmail.com \\ ${ }^{a}$ Department of Human Kinetics, School of Sciences Cross River State College of Education, Akamkpa \\ ${ }^{b}$ Department of Biology, School of Sciences Cross River State College of Education, Akamkpa \\ cDepartment of Human Kinetics, School of Sciences Cross River State College of Education, Akamkpa
}

\begin{abstract}
Epidemology studies aim at investigation of diseases prevalence on biophysical and sociocultural milleux considerations available literature reveal that there is death or near absence of information on ecological consideration in etiology of diseases in the area under consideration. This study therefore directs attention to investigation of the spatial and temporal prevalence of certain diseases in theory ecological domains. The diseases were investigated in their ecological riches. Two hypothesis were formulated and the data collected were presented tables for statistical analsysis. Two techniques were used in the analysis of data which have the one way analysis of variance(ANOVA) and the chi-square statistics. The results showed that there is a significant relationship in the spatial incidence of disease while there is no significanr rariation in the seasonal incidence.
\end{abstract}

Keyword: Ecology, Epidemological Conditions, Forest Ecotone

\section{Executive summary}

Spatial and temperal incidenc of morbility is the bedrock of epidemiological enquiry. Hence, this study was contiplated based on the sole recognition that environmental harzard and/or dieases are oftentimes environmentally and culturally determined Cross River State falls within two broad ecological zones or biomes. A biomic is a region with predominantly homegenous features interms soils, vegetations, animal life and similar climatics characteristics. In the particular essence of this study, the broad bell fall within the forest ecosystem which is equally subcategoriesd into the rainforest home to the north of the region and the marine forest ecosystem to the dieases prevalence in its' temporal and spatial distribution. For ease of data 
collection, the area desgnated clustees of subunits from which sex locations were selected on the basis of uniquences in ecological characteristics. Data was collected with a prepared check list which was administered through interview with the respondents using the defacto process of data admisnistration out the sex sampling sites , 20 respondents were selected based on considereation sex categories of 1 is to I ration. In effect ten males and ten female respondents were drawn from each sampling site. The total number of respondents were 120.8 selected dieases strains were used in the interview produre. The objective focused on eleciting information on spatial and seasonal prevalence of the selected dieases and so line with this, two hypothesis were formulated to analyse the field data collected. The hypothesis was analysed using analysis of variance and the chi-square $\left(\chi^{2}\right)$ technique

\section{Introduction}

Habitat consideration is utmost in all life forms. The emergence/ survival of individual group species of flora and fauna depend squarely on environmental niches to which the species population or community belong. Inherently, the existence of species categories in a particular location depends on adaptation or acclimatization overtime. It is Some times said and rightly too, that the biotic and abiotic components of an environment exist in a kind of amalgam or ensemble (Nwakiti 1982). Thus, the interdependence between the elements and other members of an Ecosystem satisfies the concept of ecology.

Ecological analysis is considered at different scales. Broadly, it can be considered at micro (small) scale or macro (large) scale hierarchies. Considering Cross River State as a whole, we are adopting a semi-macro scale conception due to the existence of two broad biomes or ecotones (i.e. the forest south and the savana North). These two broad regions have well defined ecosystemic niches in terms of differences in climate, edaphic, fuanistic, floristic and hydrologic characteristics. Predicated on the above, epidemiological conditions are quite variegated. Epidemiology is said to be a branch of study which focuses on environmental causation of diseases. Thus, in health literature two theories abound concerning disease causation namely the 'Germ theory' and the 'disease-environment theory'. While the former lays emphasis on causative agents such as pathogens and vectors, the latter advocates the influence of environment on disease incidence and prevalence Our concern however in this envisaged research is not to demarcate based on the argument of the two authorities above but adopt a wholesale ecological approach where the germ and environment consideration will be encapsulated.

As earlier mentioned, Cross River State belongs to two broad ecological biomes with unique ecosystemic niches. The forest south is per humid with a rainfall index of 100 .

Climatologically it belongs to 'Zone A' of the rainfall belt categories Close to the coast in the area around Calabar, marine influence is quite predominant with its unique ecological attributes (excessive flooding, water logging, favourable for disease vectors etc.). Away from the marine coast to the hinterland, other conditions prevail such as thick mass of forest vegetation presence of rugged topography in areas around Oban, Ikom and Boki Areas.

Further on to the Savanna North, Aridity prevails spatially and temporally. Spatially, some areas receive higher annual rainfall than others. Temporally, there is wide spread prevalence of seasonal draught which might be prolonged in some years. These situations provide avenues for specific categories of disease incidents.

Our Definitions of ecology is not limited to physical ecology. Social or cultural ecology is also considered where our focus is on difference in life modes among the people.

In a more simplified way we hereby categories social/cultural ecology into urban and rural ecology. The prevailing conditions among these groups have potentials of breeding specific incidents of diseases. 
They key focus of this research is to unravel disease prevalence in the context of place and people.

\section{Statement of the problem}

Assumption is quite a dangerous malady. Over time and in different places people assume events or incidents by ascription to place. For example, it is known that tsetse fly is prevalent in the forest south while mosquitoes of the anopheles type is common in the savanna north. These are vectors of diseases such as trypanosomiases and malaria respectively. Thus, by ascription our mental maps will produce images of these disease in their place context without considering exceptions to the rule. Constantly, and daily environmental changes are bringing about new strains of diseases that have not been endemic in the same areas. In a moble world of today. diseases spread or dispersal is also a common phenomenon. The constant flux of ecological changes place a great challenge on knowledge/information acquisition for man's overall sustainability.

In our villages and our urban locations, there is a high rate of death in the population. Lifestyles, environmental quality, welfarist conditions, ignorance, beliefs and what have you are all avenues of possible explanations to the morbidity/mortality incidents in our societies. These and much more comprise the ecological explanations which inform the general

aim/specific objectives of this research.

\section{Purpose / obejctives of the research}

\section{Purpose}

The overal purpose of this research ks to investigate the prevalence of diseases incidence in the forest ecological zones of Cross River State

\section{b) Specific Objectives:}

The specific objectives of these research are as follows:

- To identify spatial variation in incidence of diseases across the area

- To identify temporal variation in incidence of diseases in the area

\section{Justification of the study}

There is no disputing the fact that a study of this nature is indispensable in current times where environmental decay and dereliction have caused the proliferation of health risks and diseases of innumerable dimensions.

The all-too-importance of health matters have been recognized very early in human societies. In Nigeria for instance, different periods have been marked by formulation of national health policies (Olaniran 1995). Broadly, we can categorize the health policy frameworks into the pre-colonial and post-colonial phases. Today we are in the last phase of the post-colonial health policy formulation where Nigeria has ratified the agreement of the global health convention titled. 'The Alma Atta Declaration of 1988' in the then soviet union.

Following this, the national health philosophy predicates on social justice and equity. It was in line with this policy that the Federal Government of Nigeria Declared the year 2000 as the period for total eradication of diseases. Along this line the primary health programme was enunciated for reasons of grass root health services delivery.

This research findings will also extend the frontiers of knowledge for practitioners in environmental health epidemiology. Identification of health hazard agents by the findings of this research will provide insight into an awareness of the health status of environment by members of the general public and medical practitioners 
in particular. In this vein the study stands to provide information on the health status and the morbidity rate in the population. It is equally of vital significance in government policy formulation on matters of health.

Environmental management at all levels will undoubtedly gain inspiration from this study. Similarly, the study will provide relevant information on the need for appropriate human environmental behavior on the precinct of egocentric principle to nature's conservation.

From the results of this research, the imperative of general environmental mainstreaming in the different spheres of human existence will be called upon in such areas as general sanitation and urban waste management, change in urban planning and design, reorientation of the rural people towards adoptions and use of modern medical facilities etc. by and large, the validity of this research study as an instrument for human sustainability in different spheres of endeavor cannot be over emphasized.

\section{Research hypothesis}

Two hypothesis were slated in line with the objective as follows:

\section{Hypothsis one}

Ho: disease incidence donot vary significantly accross the different zones in the area

Hi:Diseas incidents do vary vary significantly accross the different zones in the area

\section{Hypothsis two:}

Ho: Diseas incidents do not vary significantly between the seasons (wet and dry season)

Hi: Diseas incidents do vary significantly between the seasons (wet and dry season)

\section{Scope of the study}

The study covers the entire forest ecological biome which encompases the central and southern senatoral districts of the state. This broad zone encapsulates many ecological niches as will be further discussed under area of study.

The subject scope includes the consideration of epidemiological niches of certain diseases according to habitat perculiarities, and the assessment of diseases conditions on temporal or seasonal basis as well as speccation of diseasons on criterea of epidemism, endemism and so on.

\section{Literature review}

\section{Conceptualization}

Epidemiology is the science of environmental disease inquiry. Most species have ecological adaptation according to habitat acclimatization. Diseases are also adapted to particular environment. However, the diseases that have wide or enduring spatial impact or temporal prevalence are rather described as epidemic and/or pandemic respectively.

Authorities in the field in attempting to investigate the etiology of diseases have put forward some propositions or theories to that effect. Some of these theories were highlighted to include the "Germ theory", "The xxz theory" and "the multiple factor theory", Olaniran, Akpan, Ikpeme, and Udofia (1995).

Accordingly, these scholars provided the definition of epidemiology as the study of the relationship between environmental health hazards (agents) and the environment-physical, biological, sociocultural, occupational-environmental media and man. Further on they held that epidemiology focuses on surveillance of suspected pathogens/hazards.

The close link between disease prevalence and habitat factor have been rigorously investigated and 
reported in the literature. Asogwa (1998) reported widely on certain occupation diseases related to work place environment. He reported on several occupational diseases in the field of Agriculture, industrialization and transportation.

A similar report from the book of Polular Science (1992) cited instances of certain respiratory diseases associated with work place environment such as asbestosis (from asbestos) cadmium poising diseases for those in metallurgical industries, silicosis from those working in silica industry and so on.

Another report from the World Bank (1996) focused on indoor air pollution. The greatest threat of indoor air pollution occurs in developing countries where some 3.5 million people mostly in rural areas rely on traditional fuels for cooking and heating. The report concluded that indoor air pollution is the most critical environmental problem in developing countries. From epidemiological surveys carried out in developing countries. Four categories of ailments are recognized to include, acute respiratory infections, (ARI), chronic lung cancer, still birth and other problems of birth.

A similar report from World Resources Institute (1998) stated that women exposed to smoke during cooking were three times more likely to suffer from chronic lung diseases. It was equally reported that the risk increases according to years of exposure.

Anong and Ekpo (2014) undertook a study to investigate "Environmental factors and distribution of urinary schitosomiasis in Cross River State, Nigeria". Their problem identification derived from their recognition that "Schistosomiasis remains a major health problem in Sub-Sahara Africa". The inspiration for the study was drawn from the face that Cross River State is agrarian in nature of its population and also the suitability of the environment for thriving of the snail intermediate. St S. Haematobium (Ezeke et al 1999) in the same study conducted by Ezikel (1991), he established the prevalence of urinary shistomias in Adim a rice farming commence in Cross River State with a prevalence value 4.85\%, Anong and Friday (2015).

Another finding of $44 \%$ prevalence rate was reported by Ekanem et al in Ijiman (Ugep) nearby Adim in 1995. Several studies on spatial relationships of schistosomiasis, snail intermediate hosts and water resources have been conducted at the global, regional and local levels (Dumenga et al 1995).

The current study carried out by Anong and Friday (2015) used a number of Biophysical parameters such as altitude, land surface temperature, mean annual rainfall, land use and land cover to extract conformity or nonconformity to the prevalence index of schistosomiasis incidence.

The results from the findings read as follows:

- There was a negative correlation between infection and vegetation, thus infection decreased as vegetation increased

- There was weak negative correlation, indicating that infection decreased as vegetation increased

- Temperature and infection have a positive correlation, thus infection increased land surface temperature increased

- There was a negative correlation between rainfall and temperature, hence as rainfall value increased infection decreased.

- It was also reported that infection increased as land use activities intensified

- Finally that schistosomiasis is more prevalent in laterite soil than in other categories of soils such as gravel, sand, clay and loamy soil.

These findings led to the inferences that many parasite diseases have distribution patterns influenced by environmental factors (Pavloosley 1996).

That infection is correlated with areas of high population with poor waste disposal facilities.

Another empirical inquiry on the epidemiology of blinding eye diseases by Ekpenyong (2001)) was carried out in the Department of Ophthalmology, University of Calabar, Nigeria.

The results of the findings from the study showed that there was a positive correlation of blinding eye incidence with age, sex, and occupation. It was also identified important cause of blindness in Cross River State and also that the prevalence of cataract was higher among men than women. The implication was that men engage more in outdoor work and activities than women. There was also close association between age 
and blinding eye disease as reported from the findings of the study.

It was equally reported that refractive error was the most prevalent blinding and the second most important cause of blindness in Cross River State.

It was also found and reported that glaucoma is the third most prevalent eye blinding disease in Cross River State. There was also a close correlation between the incidence of blinding eye disease and age dimension of individuals.

The fourth most important cause of blindness deriving from the result of the study was retinal/macular diseases which was discovered to increase with increasing age. children.

Finally, the prevalence of corneal disease in the study was fund to be most common in women and

Overall, the report substantiated that prevalence of blindness and blind eye disease is relatively high in Cross River State.

Another similar epidemiological case reviewes are provided by a studies undertaken by Iboh et al on "Lypathic Fillariasis among Yakurr people of Cross River State, Nigeria". (2012).

Bancrofrian fillariasis among the Mbembe people of Cross River State, Nigeria, by Okon O. E. et al (2008).

The former study by Iboh, et al focused on investigation fillariasis due to banerofli among the Yakurr people of Cross River State. 785 subjects were engaged in the study. The results revealed that of the 785, $48(6 \%)$ were positive for microfilariasis in their thick blood smear. It was also reported that there was a significance in the prevalence of microfilariasis among the various age groups. (Iboh etal 2012) and that there was no significant difference in prevalence among the different communities.

The result of the second study showed that the occurrence of microfilaria in the peripheral blood of the persons was neither age or sex determined and that most clinical manifestation were hydrocele and lympo lymphedema with overall disease prevalence of $6.8 \%$. In the report it was stated that microfilarial density is an important index in the epidemiology, treatment and control of human filiariasis in endemic foci (Ibor et al 2012).

The final case review in this literature is provided by Okon etal (2008) on Bancroflian filiariasis among the Mbembe people of Cross River State, Nigeria. This is another strain of the microfilarial pathogen that is endemic in some rural communities in Cross River State. The study aimed at investigating the prevalence of this epidemic in six villages of Obubra Local Government of Cross River State, Nigeria.

The result from the investigation showed that out of 897 persons tested, 139 representing 15.5 of the subjects tested positive. The most important clinical manifestation were hydrocele, 9.7\%, and lymphedema.

Summary

The literature directs attention to relevant explanations epistemology in its introduction. The second approach focused on case reviews whereby a few empirical studies on selected morbidity incidences were reviewed in their relevant areas. Following the reviews it became evident that incidence prevalence is environmentally and culturally determined. This finding appeals to the true perspective of epidemiological interpretation in the etiological literature

\section{Method of Study \\ Study design}

This research design falls in the domain of descriptive survey study based systematic collection analysis and interpretation of data. The design adopts a process by passive surveillance where data is gathered from traditional channels using clinical records of prevalent diseases from health institutions.

\section{Area of study}

The study area is delimited within the forest ecosystem biome of Cross River State, Nigeria. the geographical extent of the area to includes locales such as Etung, Obubra, Yakurr, Biase, Akamkpa, Odukpani, Calabar North and South, Akpabuyo and Bakassi LGAs. By area/extent, the area covers two thirds 
of the entire land mass of the state Cross River.

\section{Population of the study}

The study population comprises adult male and female residents in the domain of study which stretches from Ikom Local Government Area to the southern extremity in Bakassi Local Government Area.

\section{Sampling technique}

Sampling method employed involved multistage sampling carried out as follows:

- Area or cluster sampling based on selection of clusters representative of ecological scenarios. Hence, three clusters in the rainforest biome and three clusters in the southern marine or coasted biome. The clusters are as follows:

○ Ikom, Obubra and Akamkpa (rainforest)

- Odukpani, Calabar and Bakassi (marine).

- Purposive sampling: this involves selection according to ecological niches e.g. upland, lowland, waterland, urban, rural etc.

- On this bases twenty subjects are chosen from each of the six clusters making a total of one hundred and twenty respondents.

- Stratified sampling: this is done based on selection according to sex. On this criterion the sex ratio is 1:1 which means 60 males and 60 female respondents were used. Total number sample size is one hundred and twenty (120). See table I

TABLE I: SAMPLED POPULATION FOR THE STUDY

\begin{tabular}{|l|l|l|l|l|}
\hline Area of cluster & Biome & Male respondents & Female respondents & Total \\
\hline Ikom & Rainforest & 10 & 10 & 20 \\
\hline Obubra & Rainforest & 10 & 10 & 20 \\
\hline Akamkpa & Rainforest & 10 & 10 & 20 \\
\hline Odukpani & Rainforest & 10 & 10 & 20 \\
\hline Calabar & Marine forest & 10 & 10 & 20 \\
\hline Bakassi & Marine forest & 10 & 10 & 20 \\
\hline Grand total respondents & & $\mathbf{1 2 0}$ \\
\hline
\end{tabular}

\section{Instrument for data collection}

Interview schedule using checklist of disease prevalence

\section{Method of data collection}

Data was collected through household to household interview of adult respondents. Most time the nature of the disease category may be explained or described to the respondents for eliciting appropriate responses.

\section{Method of data analysis}

Data was analysed using the method of one way analysis of variance. 
Spatial incidence of disease prevalence in the ecological biomes

\begin{tabular}{|c|c|c|c|c|c|c|c|c|c|c|}
\hline & & \multicolumn{8}{|c|}{ DISEASE CATEGORY } & \multirow[b]{2}{*}{ Total } \\
\hline $\begin{array}{l}\text { Area/ } \\
\text { Cluster }\end{array}$ & Biome & Malaria & $\begin{array}{l}\text { Typhoi } \\
\text { d }\end{array}$ & Cholera & $\begin{array}{l}\text { River } \\
\text { blindness }\end{array}$ & $\begin{array}{l}\text { Elephenti } \\
\text { asis }\end{array}$ & $\begin{array}{l}\text { Goitr } \\
\text { e }\end{array}$ & $\begin{array}{l}\text { Catar } \\
\text { act }\end{array}$ & $\begin{array}{l}\text { Schistos } \\
\text { omiasis }\end{array}$ & \\
\hline Ikom & $\begin{array}{l}\text { Rainfor } \\
\text { est }\end{array}$ & 8 & 9 & 5 & 3 & 6 & 2 & 7 & 4 & 41 \\
\hline Obubra & $\begin{array}{l}\text { Rainfor } \\
\text { est }\end{array}$ & 9 & 7 & 6 & 4 & 1 & 1 & 6 & 6 & 42 \\
\hline $\begin{array}{l}\text { Akamkp } \\
\text { a }\end{array}$ & $\begin{array}{l}\text { Rainfor } \\
\text { est }\end{array}$ & 7 & 9 & 4 & 6 & 7 & 2 & 5 & 3 & 43 \\
\hline $\begin{array}{l}\text { Odukpan } \\
\mathrm{i}\end{array}$ & $\begin{array}{l}\text { Rainfor } \\
\text { est }\end{array}$ & 7 & 8 & 3 & 7 & 4 & 3 & 7 & 5 & 48 \\
\hline Calabar & $\begin{array}{l}\text { Marine } \\
\text { forest }\end{array}$ & 9 & 9 & 6 & 2 & 3 & 1 & 8 & 6 & 44 \\
\hline Bakassi & $\begin{array}{l}\text { Marine } \\
\text { forest }\end{array}$ & 8 & 7 & 7 & 8 & 4 & 3 & 4 & 8 & 49 \\
\hline & & 48 & 41 & 31 & 35 & 35 & 27 & 37 & 31 & 280 \\
\hline
\end{tabular}

Prevalence rating is by affirmation Yes or No among the subjects using the checklists

Seasonal incidence of disease prevalence in the ecological biomes

Table 2: Dry season incidence of disease in the ecological biomes

\begin{tabular}{|l|l|l|l|l|l|l|l|l|l|l|}
\hline $\begin{array}{l}\text { Area/ } \\
\text { Cluster }\end{array}$ & Biome & $\begin{array}{l}\text { Malari } \\
\text { a }\end{array}$ & Typhoid & Cholera & $\begin{array}{l}\text { River } \\
\text { blinesss }\end{array}$ & $\begin{array}{l}\text { Elephant } \\
\text { iasis }\end{array}$ & Goitre & Cataract & $\begin{array}{l}\text { Schist } \\
\text { osomi } \\
\text { asis }\end{array}$ & $\begin{array}{l}\text { Total } \\
\text { Ikom } \\
\begin{array}{l}12 \\
\text { Rainfor } \\
\text { est }\end{array}\end{array}$ \\
$\begin{array}{l}\text { Rainfor } \\
\text { est }\end{array}$ & 6 & 6 & 7 & 3 & 7 & 3 & 4 & 4 & 44 \\
\hline Obubra & 6 & 8 & 2 & 2 & & 2 & 5 & 40 \\
\hline $\begin{array}{l}\text { Akamkp } \\
\text { a }\end{array}$ & $\begin{array}{l}\text { Rainfor } \\
\text { est }\end{array}$ & 4 & 6 & 7 & 3 & 7 & 7 & 8 & 5 & 43 \\
\hline $\begin{array}{l}\text { Odukpa } \\
\text { ni }\end{array}$ & $\begin{array}{l}\text { Rainfor } \\
\text { est }\end{array}$ & 6 & 7 & 6 & 4 & 4 & 3 & 9 & 4 & 44 \\
\hline Calabar & $\begin{array}{l}\text { Marine } \\
\text { forest }\end{array}$ & 8 & 6 & 9 & 4 & 4 & 3 & 8 & 3 & 44 \\
\hline Bakassi & $\begin{array}{l}\text { Marine } \\
\text { forest }\end{array}$ & 9 & 6 & 7 & 6 & 7 & 6 & 7 & 2 & 49 \\
\hline
\end{tabular}

Table 2b: wet/rainy season incidence of disease in the ecological biomes

\begin{tabular}{|l|l|l|l|l|l|l|l|l|l|l|}
\hline $\begin{array}{l}\text { Area/ } \\
\text { Cluster }\end{array}$ & Biome & Malaria & Typhoid & Cholera & $\begin{array}{l}\text { River } \\
\text { blinesss }\end{array}$ & Elepha & Goitre & Cataract & $\begin{array}{l}\text { Schistos } \\
\text { omiasis }\end{array}$ & \begin{tabular}{l} 
Total \\
\hline Ikom
\end{tabular} \\
$\begin{array}{l}\text { Rainfo } \\
\text { rest }\end{array}$ & 8 & 7 & 5 & 6 & 6 & 6 & 5 & 7 & 50 \\
\hline Obubra & $\begin{array}{l}\text { Rainfo } \\
\text { rest }\end{array}$ & 7 & 8 & 5 & 7 & 8 & 4 & 6 & 8 & 53 \\
\hline $\begin{array}{l}\text { Akamkp } \\
\text { a }\end{array}$ & $\begin{array}{l}\text { Rainfo } \\
\text { rest }\end{array}$ & 8 & 7 & 3 & 4 & 5 & 4 & 7 & 6 & 41 \\
\hline $\begin{array}{l}\text { Odukpa } \\
\text { ni }\end{array}$ & $\begin{array}{l}\text { Rainfo } \\
\text { rest }\end{array}$ & 6 & 8 & 5 & 6 & 6 & 6 & 5 & 3 & 45 \\
\hline $\begin{array}{l}\text { Calabar } \\
\text { Marine } \\
\text { forest }\end{array}$ & 8 & 6 & 6 & 4 & 4 & 3 & 7 & 3 & 41 \\
\hline Bakassi & $\begin{array}{l}\text { Marine } \\
\text { forest }\end{array}$ & 6 & 8 & 7 & 8 & 6 & 4 & 7 & 4 & 50 \\
\hline & & $\mathbf{4 3}$ & $\mathbf{4 1}$ & $\mathbf{3 1}$ & $\mathbf{3 5}$ & $\mathbf{3 5}$ & $\mathbf{2 7}$ & $\mathbf{3 7}$ & $\mathbf{3 1}$ & $\mathbf{2 8 0}$ \\
\hline
\end{tabular}




\section{Data analysis}

Table 4

ANOVA of spatial incidence of diseases prevalence in the ecological Biomes

\begin{tabular}{lllll}
\hline Variable Source & Df & SS & MS & F-ratio \\
\hline Block & 7 & 5.25 & 0.75 & 0.0179 \\
\hline Treatment & 5 & 169.33 & 33.866 & 0.7719 \\
Error & 35 & 135.42 & 43.867 & \\
Total & 37 & 1710 & & \\
\hline
\end{tabular}

*Significant at 0.05

Since Fcal $=0.0170>\mathrm{F} \alpha=3.13$, we accept Ho and hence conclude that there is no significant different in spatial incidence' of diseases prevalence in the ecological biomes

Since Fcal $=0.772<\mathrm{F} \alpha=3.13$, we reject $\mathrm{Hi}$ and hence conclude that there is a significant different in spatial incidence of diseases prevalence in the ecological biomes

Table 5:

Chi square on dry season incidence of disease in the ecological biomes

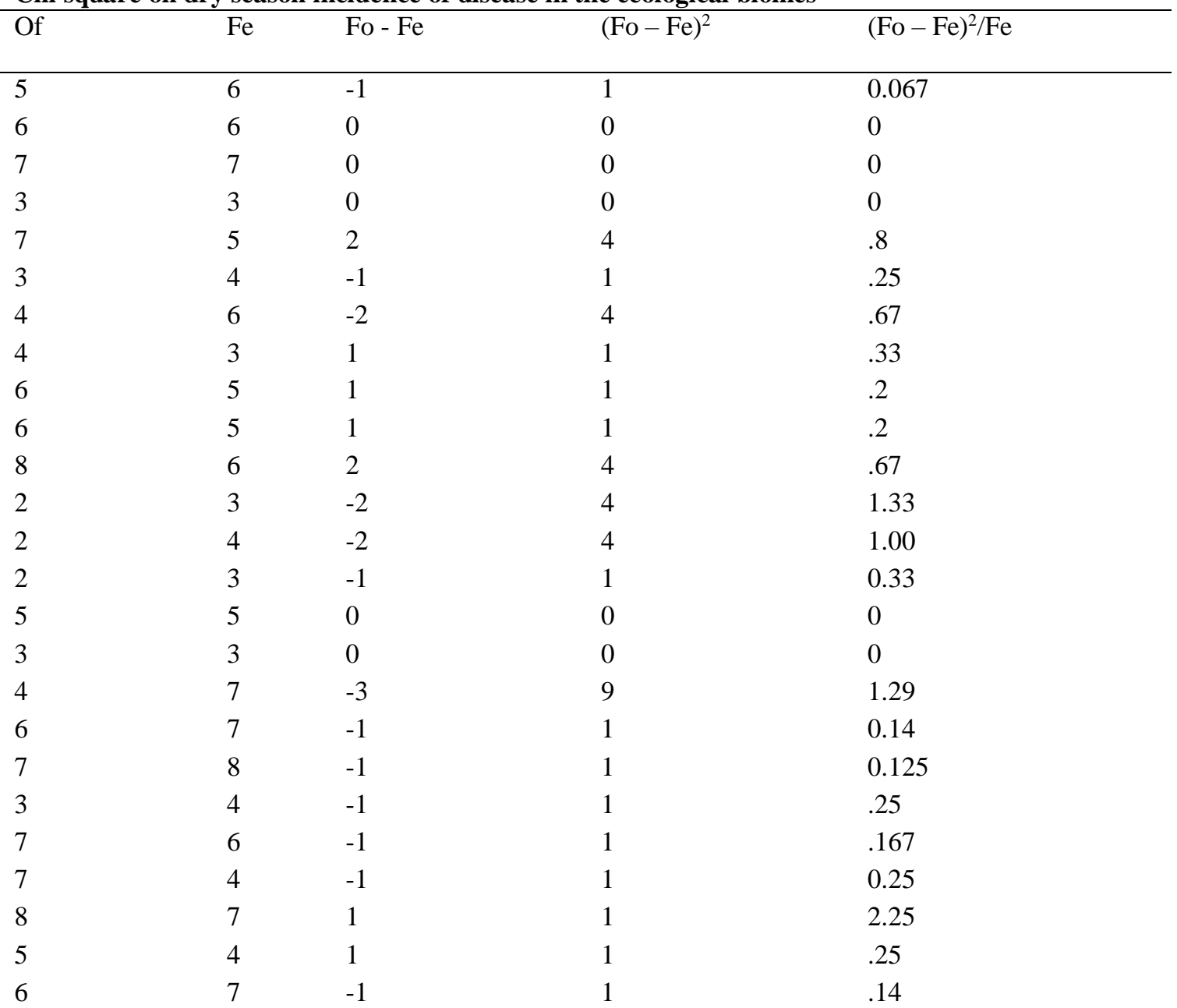




\begin{tabular}{lllll}
7 & 6 & 1 & 1 & .167 \\
6 & 8 & -2 & 4 & .50 \\
4 & 4 & 0 & 0 & 0.00 \\
5 & 6 & -1 & 1 & .016 \\
3 & 4 & -1 & 1 & .25 \\
9 & 7 & 2 & 4 & .57 \\
4 & 4 & 0 & 0 & 0 \\
8 & 7 & 1 & 1 & .14 \\
6 & 6 & 0 & 0 & 0 \\
9 & 8 & 1 & 1 & .125 \\
4 & 4 & 0 & 0 & 0 \\
4 & 6 & -2 & 4 & .66 \\
3 & 4 & -1 & 1 & .25 \\
8 & 7 & 1 & 1 & .14 \\
3 & 4 & -1 & 1 & .25 \\
9 & 7 & 2 & 4 & .57 \\
6 & 7 & -1 & 1 & .14 \\
7 & 8 & -1 & 1 & .125 \\
6 & 4 & 2 & 4 & 1.00 \\
6 & 5 & 1 & 1 & .167 \\
7 & 8 & -1 & 1 & .20 \\
2 & 4 & -2 & 4 & .125 \\
$\chi^{2}$ & & & & 16.104 \\
\hline
\end{tabular}

\section{Decision rule:}

The degree of freedom $(-1)(\mathrm{C}-1)=(6-1),(8-1)=(5,7)$ At $\alpha=0.05$ level of significance and degree of freedom 5,7. A table value of $\chi^{2}(0.05,5,7)=1.15$, and 2.17, if the computed $\chi^{2}$ is $>$ the table $\chi^{2}$ we reject the null hypothesis or otherwise if $\chi^{2}>1.15$ or $\chi^{2},<2.17$ 
Table 6

Chi square on Wet season incidence of disease in the ecological biomes

\begin{tabular}{|c|c|c|c|c|}
\hline fo & $\mathrm{Fe}$ & $\mathrm{Fo}-\mathrm{Fe}$ & $(\mathrm{Fo}-\mathrm{Fe})^{2}$ & $(\mathrm{Fo}-\mathrm{Fe})^{2} / \mathrm{Fe}$ \\
\hline 8 & 8 & 0 & 0 & 0 \\
\hline 7 & 7 & 0 & 0 & 0 \\
\hline 5 & 6 & -1 & 1 & .167 \\
\hline 6 & 6 & 0 & 0 & 0 \\
\hline 6 & 6 & 0 & 0 & 0 \\
\hline 6 & 6 & 0 & 0 & 0 \\
\hline 5 & 7 & -2 & 4 & .57 \\
\hline 7 & 6 & 1 & 1 & 1.67 \\
\hline 7 & 8 & -1 & 1 & .125 \\
\hline 8 & 8 & 0 & 0 & 0 \\
\hline 5 & 6 & -1 & 1 & .167 \\
\hline 7 & 7 & 0 & 0 & 0 \\
\hline 8 & 7 & 1 & 1 & .14 \\
\hline 4 & 5 & -1 & 1 & .2 \\
\hline 6 & 7 & -1 & 1 & .14 \\
\hline 8 & 6 & 2 & 4 & .7 \\
\hline 8 & 6 & 2 & 4 & .7 \\
\hline 4 & 6 & -2 & 4 & .7 \\
\hline 3 & 5 & -2 & 4 & .8 \\
\hline 4 & 5 & -1 & 1 & .2 \\
\hline 5 & 4 & 1 & 1 & .25 \\
\hline 4 & 5 & -1 & 1 & .2 \\
\hline 7 & 5 & 2 & 4 & .8 \\
\hline 6 & 7 & -1 & 1 & .14 \\
\hline 6 & 7 & -1 & 1 & .14 \\
\hline 8 & 5 & 3 & 9 & 1.8 \\
\hline 5 & 6 & -1 & 1 & .7 \\
\hline 6 & 6 & 0 & 0 & 0 \\
\hline 6 & 4 & 2 & 4 & 1.0 \\
\hline 5 & 6 & -1 & 1 & .17 \\
\hline 3 & 5 & -2 & 4 & .8 \\
\hline 8 & 6 & 2 & 4 & .7 \\
\hline 6 & 6 & 0 & 0 & 0 \\
\hline 6 & 5 & 1 & 1 & .2 \\
\hline
\end{tabular}




\begin{tabular}{lllll}
4 & 5 & -1 & 1 & .2 \\
4 & 5 & -1 & 1 & .2 \\
3 & 4 & -1 & 1 & .3 \\
7 & 5 & 2 & 4 & .8 \\
3 & 5 & -2 & 4 & .8 \\
6 & 8 & -2 & 4 & .5 \\
8 & 7 & 1 & 1 & .14 \\
7 & 6 & 1 & 1 & .17 \\
8 & 6 & 2 & 4 & .7 \\
6 & 6 & 0 & 0 & 0 \\
4 & 5 & -1 & 1 & .2 \\
7 & 7 & 0 & 0 & 0 \\
4 & 6 & -2 & 4 & .7 \\
$\chi^{2}$ & & & & $\mathbf{1 7 . 8 8 9}$ \\
\hline
\end{tabular}

\section{Decision rule:}

The degree of freedom (-1) $(\mathrm{C}-1)=(6-1),(8-1)=(5,7)$ At $\alpha=0.05$ level of significant and degree of freedom 5,7. A table value of $\chi^{2}(0.05,5,7)=1.15$, and 2.17, if the computed $\chi^{2}$ is $>$ the table $\chi^{2}$ we reject the null hypothesis or otherwise if $\chi^{2}>1.15$ or $\chi^{2},<2.17$

\section{Findings/results}

Two hypotheses were utilized in the analyses. The first directs attention to analsysis of epidemiological conditions n spatial basi. The second hypothesis focused on analysis of season trends in the epidemological incidents of diseases.

Hypothesis I: was tested using the technique of two ways analysis of variance. Following the result, the calculated value of of F-ratio is greater than the critical table value $(\alpha)$ we conclude that there is significance in disease prevalence across the different ecological matches in the area under investigation. This result tallies with earlier studies conducted on similar lines such as that by Annong et. al (2014) on "environmental factors and distribution of curinary schistosamiasis in Cross River State Nigeria" citing pavlovsky, 1966, the declared that many parasitic diseases have distribution patterns influenced by environmental factors suing a number of ecological variables, his findings were that; (1) that there s a negative correlation between schislonuasis. He categorically stated that learning schistosomiasis increased as vegation cover increased. Booker et al (2001) also investigated the similar incidence in tanzania and coe out with a result that was comformal to that of anong (ii) the second index of rainfall was also investigated and the result showed that there was a positives correlation between schistosomiasis prevalence and rainfall availability, Higher rain incidence means higher prevalence because rainfall provides a suitable environment for breding of snail which the intermediate host (iii) The index of altitude and prevalence of the schistomiases disease was equally explored and reforest showed a nagtive correlation between prevalence of schistosomiasis and increasing ascent above the level. Hence lower ground present more suitable environment for breeding of the disease than higher grounds(iv) equally it was discovered that there was a positive correlation between temperature and prevalence of schistosomiasis incidence. The report held that schistosomiasis increased ad the mean land surface temperature increases. Other indices of population sizes, land use/human activity and soil type ware all explored withcircumspect findings.

Spatila variation in diseaes ecology may be explained by other variable such as demographic characteristics, 
income level, life styles. Ibor and Okonkwor (2019) study on demographic and socio-ecobomic factors inluncing malaria in Calabarl lend support to the above allusion. In the their report they reasoned may affect the level of susuptibility of the individual to malarial infesion. Thus low income earners are siad to more vunerable to the incidence of insfestation becauses of corresposndingly low standard of living. It was further hilighted in the report that areas where the low income live provide fertitle breeding grounds to matured vectors (mosquitoes)

Hypothesis 2 follows the investigation of diseas prevalence on temporal or seasonal basis. The result of the hypothesis testing favoured the recreation of the alternative hypothesis and the acceptance of the null hypothesis. This means that there is no significance on seasonal basis this however does not foreclose the fact that some environmental diseases occur in time productivity. For instance, Ibor et al (2017) in the investigation discovered that malaria incidents were more common in the wet season than in the dry diceto a number of related factors such as availability of favourable breeding grounds for the parasites (mosquito) suitable habitat for thriving of vectors and others. Similarrly Anong et al survey of urinaring schistosomiasis in yakurrr revealed interesting insights from the princent that temperature increase and the prevalence of the disease were positively xorrelated. It is also practically evidence that certain environmental diseases like inlfuenza, measles, chikken pox and so on due occur on seasonal periodicity.

\section{Conclusion}

From authentative sources in literature and other outlets it has become evident that extent previal in habitat niches or temporal periodicity. A good knowledge of this health states management and control. Individuals government and all environmental stake holder, need information for sound health management

\section{References}

Anong, G. and Ekpo, F.U. 2014. "Environmental factors and distribution of urinary schistosomiasis in Cross River State, Nigeria, Inter Journal of Zoological Research, ISSN18119778/Dol:10,3923/11zr 2014. 
Academic Journal Inc.

Asogwa, S.E. 1978. A guide to occupational health practice in developing countries, Enugu, Fourth Dimension Publishers.

Doumenga, J.P., Mott, J.K.E., Chueng, D. Chappius, M.F. and Thomas, G. R. 1987..Atlas of Global Distribution of Schistosomiasis.World Health Organization (WHO) Geneva, Switzerland.In Anong, G. and Ekpo, F. 2014. Environmental factors in the distribution of urinary schistosomiasis in Cross River State, Nigeria. International Journal of Zoological Research.

Egekel, Braite E.A and Ekanem. E.E 1999. A. survey of prevalence of haematobuim in Adim Nigeria . Afield survey report by the faculty of Biological Science University of Calabar.

Ejezee, G.C, Uko, I.E. and Braid, I.E. 1991.Schistosomiasis in Cross River State, Nigeria: Prevalence and intensification of infection in Adim, Akamkpa Local Government Area, J. HYG. Epidemio.Microbiol.Immunol. 35, 141-147.

Ekanem, E.E. , Ejeze, Antia,E.O. Urinary symplons and Blood pressure of chrildren with histomia Heamatcbuim inflection in southern eastern Nigeira Easte Africa Med . J 72 . 486-495.

Ekpeyong (2001) Epidemiology of blinding eye disease in Cross River State, Nigeira As seen in University of Calabar teahing hospital. Aseminar paper ,Department of of Ophthalmotogy University of Calaabr, Cross River State.

Iboh, C.I., Okon, E.O., Okpara, E.K, Asor, J.E. and Etim, S.E. 2017. Lymphatic filiariasis among the Yakurr people of Cross River State Nigeria, parasites and vectors volume 5, Article number 203 (2012) cite this article 5349 accesses.

Nwankite I.E. (1982) Man and environment enugu, fourth Dimension publisher

Okon, E.O, Iboh, C.I. and Opara K.N. Bancroflianfilariasis among the Mbembe people of Cross River State, Nigeria, Affiliation expand, PMID 20539046.

Olaniran, I.S., Akpan, A., Ikpeme, S. and Udofia, A. 1995.Environment and Healtth; Ibadan, Intec.Publication.

Pavloosky, E.N. 1996. The National Nidality of Transmissible Diseases, University of Illinois Press, Urbana, Illinois.In Anong and Ekpo 1991. Factors and distribution of urinary schistosomiasis in Cross River State, Nigeria.

World Bank 1996. Some contemporary problems in research in air pollution in board chorley (Ed) progress in geography, International Review of Current Research, Butter and Tanner LTD (8), 75-132.

World Resources 1998.Health and Environment. Health Effects of Air Pollution, Oxford University Press (International). 